\title{
ALTURA DE PLANTA E ACÚMULO DE MATÉRIA SECA DO FEIJOEIRO CVS. BRS MG TALISMÃ E OURO NEGRO EM PLANTIO DIRETO E CONVENCIONAL ${ }^{1}$
}

\author{
Plant height and dry matter acumulation by common bean cvs. BRS MG Talismã and \\ Ouro Negro under no-tillage and conventional crop systems
}

\author{
Neiva Maria Batista Vieira², Messias José Bastos de Andrade ${ }^{3}$, \\ Janice Guedes de Carvalho ${ }^{4}$, Jainir Alves Junior 5 , Augusto Ramalho Morais ${ }^{6}$
}

\begin{abstract}
RESUMO
Com o objetivo de estudar a curva de crescimento em altura de planta, taxa e acúmulo de matéria seca da parte aérea ao longo do ciclo cultural do feijoeiro (Phaseolus vulgaris L.) foram conduzidos quatro experimentos de campo, com as cvs. Ouro Negro e BRS MG Talismã, em plantio direto e convencional, sendo um em Lavras (Latossolo Vermelho distroférrico típico, inverno primavera 2002) e os demais em Madre de Deus de Minas (Latossolo Vermelho Amarelo ácrico, seca 2005). O delineamento experimental foi feito com blocos casualizados com três repetições e 11 ou 12 tratamentos (épocas de coleta). De 7 em 7 dias foram amostradas 10 ou 20 plantas para determinação da altura, através do comprimento da haste principal, e outras 20 plantas para determinação do peso da matéria seca da parte aérea após secagem em estufa com circulação de ar a $65-70^{\circ} \mathrm{C}$ até peso constante. Os dados foram submetidos a análises de variância e regressão, com ajuste de curvas representativas do comportamento das características avaliadas. Em plantio direto, a altura máxima foi alcançada aos 50 DAE, enquanto no plantio convencional o feijoeiro continuou crescendo até os 72-73 DAE, ocorrendo fechamento mais tardio da lavoura. As cvs. Ouro Negro e BRS MGTalismã mostraram padrões de acúmulo de matéria seca muito próximos, com pouco incremento até os 81 DAE, na BRS MG Talismã, e ambas alcançaram maiores acúmulos em plantio direto. Em geral, as maiores taxas de acúmulo de matéria seca foram verificadas entre 45-48 DAE.
\end{abstract}

Termos para indexação: Crescimento, sistemas de plantio, genótipos, Phaseolus vulgaris.

\begin{abstract}
The aim of this research was to study the plant growth in height and the dry matter accumulation pattern along the bean (Phaseolus vulgaris L.) crop cycle. Four field experiments were carried out in Lavras (winter-spring 2002) and other were performed in Madre de Deus de Minas, MG (dry crop season 2005) with common bean, cvs. Ouro Negro and BRS MG Talismã, under no-tillage and conventional crop systems. Every seven days 10 or 20 plants were sampled to height measurements and other 20 plants for dry matter evaluation. The experiments were carried out in randomized block outlines with three replications and 11 or 12 treatments (sampling times). The data were treated with a variance and regression analysis and representative curves of the evaluated variables were fitted and adjusted. The growth curves had showed that the maximum height was reached by the 50 DAE in no-tillage crop system while in the conventional crop system the bean kept on growing up to the 72-73 DAE, closing further in field. The pattern of dry matter accumulation showed that there was a small increment until the 21-24 DAE for the two cultivars. The maximum accumulation could be observed in the no-tillage croping systems by the 75-76 DAE for the cv. Ouro Negro and by the 80-81 DAE for the cv. BES MG Talismã. In general, the highest rates of dry matter accumulation were verified by the 45-48 DAE.
\end{abstract}

Index terms: Growth, crop systems, genotypes, Phaseolus vulgaris.

(Recebido em 27 de abril de 2006 e aprovado em 24 de maio de 2007)

\section{INTRODUÇÃo}

De acordo com Magalhães (1979), o crescimento de um vegetal apresenta um período inicial lento, seguido de uma fase de rápido aumento de tamanho e acúmulo de matéria seca e, finalmente, há um decréscimo no acúmulo de matéria orgânica e do crescimento em altura. O feijoeiro apresenta uma fase inicial de crescimento relativamente lento até os 20 dias após emergência (DAE), uma fase intermediária, em que ocorrem as maiores taxas de

\footnotetext{
${ }^{1}$ Parte da dissertação do primeiro autor, apresentada à UFLA, para obtenção do Título de Mestre - Trabalho financiado pela FAPEMIG ${ }^{2}$ Engenheira Agrônoma, Doutoranda em Fitotecnia - Universidade Estadual de Montes Claros/UNIMONTES - Rua Reinaldo Viana, 2630 - Bico da Pedra - 39440-000 - Janaúba, MG - neiva-vieira@uol.com.br

${ }^{3}$ Engenheiro Agrônomo, Doutor em Fitotecnia, Professor - Departamento de Agricultura/DAG - Universidade Federal de Lavras/UFLA - Cx. P. 3037 372000-000 - Lavras, MG - mandrade@ufla.br - Bolsista CNPq

${ }^{4}$ Engenheira Agrônoma, Doutora em Solos e Nutrição de Plantas, Professora - Departamento de Ciência do Solo/DCS - Universidade Federal de Lavras/ UFLA - Cx. P. 3037 - 372000-000 - Lavras, MG - janicegc@ufla.br - Bolsista CNPq

${ }^{5}$ Engenheiro Agrônomo, Mestre em Fitotecnia - Departamento de Agricultura/DAG - Universidade Federal de Lavras/UFLA - Cx. P. 3037 - $37200-000$ Lavras, MG - jainir@atualempresarial.com.br

${ }^{6}$ Engenheiro Agrônomo, Doutor em Estatística e Experimentação Agronômica, Professor - Departamento de Ciências Exatas/DEX - Universidade Federal de Lavras/UFLA - Cx. P. 3037 -372000-000 - Lavras, MG - amorais@ufla.br - Bolsista CNPq
} 
crescimento e uma fase final em que há diminuição desse crescimento (ALMEIDA \& BULISANI, 1980; BULISANI, 1994; HAAG et al., 1967). Com relação ao acúmulo de matéria seca, esse período pode variar dos 35 aos 63-70 DAE (GOMES et al., 2000).

Desde o século passado (EMERSON, 1916), sabese que o crescimento do feijoeiro em altura é bastante influenciado pelo ambiente e pelas condições de manejo. Estudos realizados por Jauer et al. (2003) em diferentes densidades de semeadura concluíram que o acúmulo de matéria seca foi crescente até os 75 DAE, variando de 692,6 a 693,17 g.m ${ }^{-2}$, sendo que aos 30 DAE as maiores populações apresentaram os maiores acúmulos. Além da densidade de semeadura (BRANDES et al., 1972), a época de plantio (XAVIER, 1976) e o manejo da irrigação (TELES NETO, 2001) são fatores relevantes quando se analisa o crescimento do feijoeiro, sendo encontradas alturas máximas de 55 a $140 \mathrm{~cm}$, entre 30 e 88 DAE e máximas taxas de acúmulo de matéria seca entre 30 e 50 DAE.

Também há grande variação entre cultivares. Segundo Rosolem (1987), durante o florescimento da cv. Carioca, que compreende o período entre 45 e 55 DAE, é que se observa a maior velocidade de produção e de acúmulo de matéria seca alcançando, na maturação, o quádruplo de matéria seca em relação ao florescimento. Gallo \& Miyasaka (1961), estudando a cv. Chumbinho Opaco, constataram que a matéria seca na maturação corresponde a duas vezes a matéria seca existente no florescimento. Andrade et al. (2005), entretanto, constataram que os valores do acúmulo de matéria seca total das cvs. BRS MG Talismã e Ouro Negro, em plantio convencional, foram inicialmente muito próximos, sendo que, a partir dos 36 DAE a cv. Ouro Negro teve uma acumulação maior de matéria seca atingindo, aos 76 DAE, o máximo de 998,04 g.m-2 , contra 709,47 g.m-2 da cv. BRS MG Talismã.

Objetivou-se com este trabalho estudar o crescimento do feijoeiro comum, cvs. BRS-MG Talismã e Ouro Negro, em sistema de plantio direto e convencional, por meio da altura de planta, bem como da taxa de acúmulo e acúmulo total de matéria seca na parte aérea.

\section{MATERIALE MÉTODOS}

O estudo constou de quatro experimentos de campo. O primeiro deles, com a cv. BRS MG Talismã em sistema convencional, foi instalado em área do Departamento de Agricultura da Universidade Federal de Lavras (UFLA), em um Latossolo Vermelho distroférrico típico, no inverno-primavera de 2002. Os demais foram instalados em um Latossolo Vermelho Amarelo ácrico da
Fazenda Ouro Fino, município de Madre de Deus de Minas (Tabela 1), no verão-outono de 2005, com a cv. Ouro Negro, em plantio direto e convencional, e com a cv. BRS MG Talismã em plantio direto.

Acv. BRS MG Talismã apresenta grãos tipo carioca, crescimento indeterminado com guias longas (tipo III), porte prostrado, ciclo médio de 85 dias, resistência à raça alfa brasil (patótipo 89) de antracnose (Colletotrichum lindemuthianum) e ao mosaico comum (VMCF) e resistência intermediária à mancha angular (Phaeoisariopsis griseola) (Cultivar..., 2002). A cultivar Ouro Negro, de grãos pretos, apresenta hábito de crescimento indeterminado com guias longas (tipo III), porte prostrado, ciclo normal (90 dias), alta capacidade de fixação simbiótica de nitrogênio, resistência à ferrugem e antracnose e tolerância ao frio (Informativo..., 1997).

No estudo dos efeitos das cultivares e dos sistemas de plantio sobre a altura de planta e acúmulo de matéria seca da parte aérea, utilizou-se o delineamento estatístico de blocos casualizados, com três repetições e esquema fatorial $2 \times 2$ envolvendo as duas cultivares (Ouro Negro e BRS MG Talismã) e os dois sistemas de plantio (Plantio Direto e Convencional).

No estudo do comportamento da altura e do acúmulo de matéria seca ao longo do ciclo o delineamento estatístico foi o de blocos casualizados, com três repetições e onze tratamentos (épocas de coleta) no ensaio da cv. Ouro Negro em plantio convencional e doze nos demais ensaios. No plantio direto, a primeira coleta foi realizada aos 10 DAE na cv. Ouro Negro e aos 12 DAE na BRS MG Talismã, enquanto no sistema convencional ela ocorreu aos 5 DAE na Ouro Negro e aos 7 DAE na BRS MG Talismã. Em cada coleta, feita de 7 em 7 dias, foram amostradas dez plantas no ensaio de Lavras e vinte plantas nos demais ensaios, medindo-se a altura, desde o colo até a inserção da última folha trifoliolada completamente expandida. Outras vinte plantas foram também amostradas cortandoas a $1 \mathrm{~cm}$ do solo, sendo posteriormente o material seco em estufa com circulação de ar a $65^{\circ} \mathrm{C}$ a $70^{\circ} \mathrm{C}$ até peso constante e, finalmente, pesado em balança de precisão, determinando-se então o peso da matéria seca da parte aérea. As taxas de acúmulo de matéria seca foram calculadas a partir das equações ajustadas.

No plantio direto, os ensaios foram instalados em locais sob palhada de milho, estimada em $3.817,6 \mathrm{~kg} \mathrm{ha}^{-1}$ por meio de três amostragens com um quadro com $0,25 \mathrm{~m}^{2}$ de área. A dessecação foi realizada quinze dias antes do plantio, com 2,5 kg de Roundup WGÒ por hectare. No plantio convencional, em ambas as localidades, o preparo do solo constou de uma aração e uma gradagem pesada. 
Tabela 1 - Resultados da análise química de amostras de material dos solos utilizados (camada 0-20 cm). UFLA, Lavras, MG 2006.

\begin{tabular}{|c|c|c|c|}
\hline \multirow{2}{*}{ Características } & \multirow{2}{*}{$\begin{array}{c}\text { Lavras } \\
\text { PC }\end{array}$} & \multicolumn{2}{|c|}{ Madre de Deus de Minas } \\
\hline & & PD & $\mathrm{PC}$ \\
\hline $\mathrm{pH}$ em $\mathrm{H}_{2} \mathrm{O}(1: 2,5)$ & $5,3 \mathrm{AcM}$ & 5,9 AcM & $5,6 \mathrm{AcM}$ \\
\hline $\mathrm{P} \mathrm{mg} \mathrm{dm}$ & $15,0 \mathrm{~B}$ & $5,2 \mathrm{Ba}$ & $0,9 \mathrm{MBa}$ \\
\hline $\mathrm{K} \mathrm{mg} \mathrm{dm}{ }^{-3(1)}$ & $61,0 \mathrm{M}$ & $98,0 \mathrm{~B}$ & $39,0 \mathrm{Ba}$ \\
\hline Ca cmolc dm ${ }^{-3(2)}$ & $1,8 \mathrm{M}$ & 4,3 MB & $2,3 \mathrm{M}$ \\
\hline $\mathrm{Mg}$ cmolc $\mathrm{dm}^{-3(2)}$ & $0,5 \mathrm{M}$ & $1,7 \mathrm{MB}$ & $1,3 \mathrm{~B}$ \\
\hline Al cmolc dm ${ }^{-3(2)}$ & $0,2 \mathrm{Ba}$ & $0,0 \mathrm{MBa}$ & $0,0 \mathrm{MBa}$ \\
\hline $\mathrm{H}+\mathrm{Al} \mathrm{cmolc} \mathrm{dm}^{-3(3)}$ & $4,5 \mathrm{M}$ & $3,2 \mathrm{M}$ & $4,0 \mathrm{M}$ \\
\hline SB (Soma de bases) cmolc $\mathrm{dm}^{-3}$ & $2,5 \mathrm{M}$ & 6,3 MB & $3,7 \mathrm{~B}$ \\
\hline $\mathrm{t}$ (CTC efetiva) cmolc $\mathrm{dm}^{-3}$ & $2,7 \mathrm{M}$ & $6,3 \mathrm{~B}$ & $3,7 \mathrm{M}$ \\
\hline 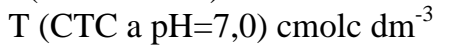 & $7,0 \mathrm{M}$ & $9,4 \mathrm{~B}$ & 7,7 M \\
\hline Saturação por alumínio (m) \% & $8,0 \mathrm{MBa}$ & $0,0 \mathrm{M} \mathrm{Ba}$ & $0,0 \mathrm{MBa}$ \\
\hline Saturação por bases (V) \% & $35,3 \mathrm{Ba}$ & $66,1 \mathrm{~B}$ & $48,1 \mathrm{M}$ \\
\hline $\mathrm{S} \mathrm{mg} \mathrm{dm}-3(4)$ & $44,8 \mathrm{MB}$ & $12,8 \mathrm{MB}$ & $10,8 \mathrm{MB}$ \\
\hline Matéria Orgânica dag kg- ${ }_{-}^{1(5)}$ & $1,8 \mathrm{M}$ & $2,1 \mathrm{M}$ & $2,2 \mathrm{M}$ \\
\hline $\mathrm{Zn} \mathrm{mg} \mathrm{dm}{ }^{-3(1)}$ & $14,5 \mathrm{~A}$ & $13,1 \mathrm{~A}$ & $2,4 \mathrm{~A}$ \\
\hline $\mathrm{Fe} \mathrm{mg} \mathrm{dm}^{-3(1)}$ & $42,0 \mathrm{~B}$ & $78,9 \mathrm{~A}$ & $89,2 \mathrm{~A}$ \\
\hline Mn mg dm ${ }^{-3(1)}$ & $19,0 \mathrm{~A}$ & $12,3 \mathrm{~A}$ & $7,5 \mathrm{M}$ \\
\hline $\mathrm{Cu} \mathrm{mg} \mathrm{dm}{ }^{-3(1)}$ & $3,7 \mathrm{~A}$ & $1,9 \mathrm{~A}$ & $2,6 \mathrm{~A}$ \\
\hline $\mathrm{B} \mathrm{mg} \mathrm{dm}{ }^{-3}(6)$ & $0,3 \mathrm{Ba}$ & $0,4 \mathrm{M}$ & $0,3 \mathrm{Ba}$ \\
\hline
\end{tabular}

* Análises realizadas pelo Laboratório de Fertilidade do Solo do Departamento de Ciência do Solo da UFLA e interpretação de acordo com a Comissão de Fertilidade do Solo do Estado de Minas Gerais, 5a . aproximação (Ribeiro et al., 1999). (1) Extrator Mehlich, (2) Extrator KCl $1 \mathrm{~N},{ }^{(3)}$ Extrator SMP, ${ }^{(4)}$ Extrator Fosfato Monocálcico em ácido acético, (5) Oxidação: $\mathrm{Na}_{2} \mathrm{Cr}_{2} \mathrm{O}_{7}$ $4 \mathrm{~N}+\mathrm{H}_{2} \mathrm{SO}_{4} 10 \mathrm{~N}$, (6) Extrator água quente, $\mathrm{AcM}=$ Acidez Média, $\mathrm{MBa}=$ Muito baixo, $\mathrm{Ba}=\mathrm{Baixo}, \mathrm{M}=\mathrm{Médio}, \mathrm{B}=\mathrm{Bom}, \mathrm{MB}=\mathrm{Muito}$ Bom, $\mathrm{A}=$ Alto.

Não foi feita a correção do solo, com exceção do experimento da cv. Ouro Negro em plantio convencional, onde foram aplicadas 4 t.ha ${ }^{-1}$ de calcário dolomítico. A adubação de plantio foi $400 \mathrm{~kg} \cdot \mathrm{ha}^{-1}$ do formulado 08-28-16 (32 kg.ha-1 de N, 112 kg.ha ${ }^{-1}$ de P e 64 kg.ha-1 de K) em Lavras e $500 \mathrm{~kg} \cdot \mathrm{ha}^{1}$ do formulado $10-30-10\left(50 \mathrm{~kg} \cdot \mathrm{ha}^{-1}\right.$ de $\mathrm{N}, 150 \mathrm{~kg} \cdot \mathrm{ha}^{-1}$ de $\mathrm{P}$ e $50 \mathrm{~kg} \cdot \mathrm{ha}^{-1}$ de $\left.\mathrm{K}\right)+$ micronutrientes $(0,5$ kg.ha- ${ }^{-1} \mathrm{Zn}$ e 0,06 kg.ha- ${ }^{-1}$ de B) em Madre de Deus. Ainda nesta localidade, quando as plantas se encontravam no estádio $\mathrm{V}_{3} / \mathrm{V}_{4}$ (FERNANDEZ et al., 1985), foram aplicados, via foliar, $150 \mathrm{~g} \cdot \mathrm{ha}^{-1}$ de molibdato de sódio e realizada a adubação de cobertura, aplicando-se mecanicamente 200 $\mathrm{kg} \mathrm{ha}^{-1}$ do formulado $30-00-10\left(60 \mathrm{~kg}\right.$ de $\mathrm{N}+20 \mathrm{~kg}$ de $\left.\mathrm{K}_{2} \mathrm{O}\right)$ em sulcos laterais às linhas de plantio, com incorporação. No experimento de Lavras a adubação de cobertura foi feita manualmente e constou de $30 \mathrm{~kg} \mathrm{ha}^{-1} \mathrm{de} \mathrm{N}$., fonte uréia.

Em Lavras, a semeadura foi manual, adotando-se a densidade de 16 sementes por metro e parcelas de quatro linhas de $5 \mathrm{~m}$ de comprimento, sendo a área útil constituída pelas duas linhas centrais. Em Madre de Deus foram utilizadas três glebas comerciais, semeadas mecanicamente com a densidade de 15 sementes por metro e as amostragens foram realizadas diretamente nos talhões. $\mathrm{O}$ espaçamento entre linhas foi sempre de $0,5 \mathrm{~m}$.

Para controle das plantas daninhas, em Madre de Deus foi aplicada uma mistura de $300 \mathrm{ml}$ de Flex ${ }^{\circledR}+1 \mathrm{~L}$ de Podium $+500 \mathrm{ml}$ de óleo mineral Attach por hectare, enquanto em Lavras o controle foi manual, com enxadas. Os demais tratos culturais foram os normalmente dispensados à cultura na região. Os ensaios instalados em Madre de Deus não receberam irrigação e o ensaio de Lavras foi irrigado por aspersão convencional, sempre que necessário.

Por se tratar de área comercial, nos ensaios instalados em Madre de Deus de Minas foram adotados os mesmos procedimentos e tratos culturais utilizados pelo produtor.

Todos os dados foram submetidos à análise de variância. Para a comparação entre as médias de cultivares e sistemas de plantio foi utilizado o teste de Tukey ao nível de 5\% de probabilidade. No estudo da altura de planta e acúmulo de matéria seca da parte aérea ao longo do ciclo 
cultural, os dados foram submetidos também à análise de regressão. As épocas e as quantidades de matéria seca acumuladas, bem como a altura máxima alcançada pelas plantas, foram estimadas com base nos modelos não linear logístico, no caso da altura de planta dos ensaios de Madre de Deus de Minas, e cúbico nas demais situações.

\section{RESULTADOS E DISCUSSÃO}

De acordo com a análise de variância conjunta, a altura das plantas foi influenciada pelos sistemas de plantio e pela interação cultivares x sistemas, apresentando boa precisão experimental. Nesta análise, o comportamento das cultivares não foi consistente e foi diferenciado em função do sistema de plantio: a cv. Ouro Negro apresentou maior altura no plantio direto $(101 \mathrm{~cm})$, enquanto a cv. BRS MG Talismã cresceu mais no plantio convencional $(97 \mathrm{~cm})$. As médias gerais das cultivares, entretanto, foram muito próximas, da ordem de 90 a $93 \mathrm{~cm}$ (Tabela 2).

O comportamento da altura das plantas nas diferentes épocas de amostragem é mostrado nas Figura 1, onde se observa que também houve bom ajuste dos dados ao modelo ajustado em cada caso. No plantio direto, ambas as cultivares apresentaram incrementos significativos na altura de planta até aos $50 \mathrm{DAE}$, quando apresentaram certa estabilidade (Figura 1). A cv. Ouro Negro apresentou altura máxima de $109 \mathrm{~cm}$ e a cv. BRS MG Talismã, de $100 \mathrm{~cm}$. Este resultado, de certa forma, é compatível com os encontrados por Brandes et al. (1972), nos quais a maior altura de planta também foi encontrada aos 50 DAE em plantios com densidades de 125 e 250 mil plantas.ha ${ }^{-1}$.

No sistema convencional, a cv. Ouro Negro alcançou a altura máxima de 73 centímetros aos 40 DAE, e a partir daí estabilizou-se. Neste mesmo sistema a cv. BRS MG Talismã somente atingiu o ponto de máximo, de $110 \mathrm{~cm}$, aos 72 DAE e apresentou, nos estádios finais, ligeiro decréscimo (Figura 1). Este último comportamento foi o que mais se aproximou dos encontrados na literatura clássica sobre o comportamento do acúmulo de matéria seca ao longo do ciclo cultural do feijoeiro (Cobra Netto, 1967; Gallo \&
Miyasaka, 1961; Haag ET AL., 1967), justamente pelo fato de apresentar este decréscimo final. Certamente, as diferenças de comportamento não podem ser creditadas somente ao fator cultivar, pois foram diferentes as condições de solo (Tabela 1) e clima. Entretanto, algumas características das cultivares, como ciclo, porte e arquitetura, poderiam estar envolvidas.

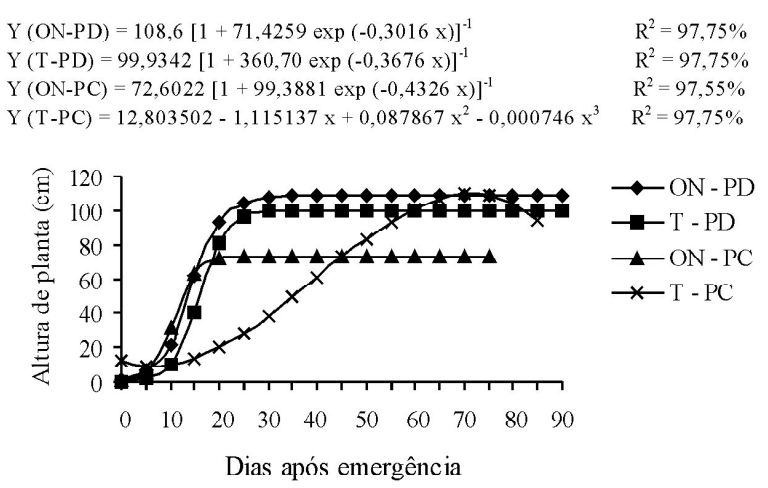

Figura 1 - Altura de planta $(\mathrm{cm})$ em função de dias após emergência, em plantio direto (PD) e convencional (PC), cvs. Ouro Negro (ON) e Talismã (C).

Nota-se que, em geral, as plantas apresentaram altura máxima entre 100 e 109 centímetros, exceto a cultivar Ouro Negro em plantio convencional (Figura 1). Esta diferença em altura pode ser atribuída ao fato de que o respectivo experimento foi instalado em gleba de primeiro ano, situação na qual geralmente as plantas crescem menos. Neste sentido, algumas diferenças de fertilidade do solo podem ser observadas na Tabela 1 .

A análise de variância conjunta dos dados relativos ao acúmulo máximo de matéria seca mostrou que esta característica foi influenciada pelas cultivares de feijoeiro, com registro de significância também para a interação cultivares x sistemas de plantio, com precisão experimental satisfatória, neste caso. Tanto no plantio direto, como no convencional, a cv. BRS MG Talismã produziu mais matéria seca que a cv. Ouro Negro (Tabela 2). As cvs. BRS MG

Tabela 2 - Valores médios da altura final de planta $(\mathrm{cm})$ e do acúmulo máximo de matéria seca total (kg.haª $\left.{ }^{-1}\right)$ das cvs. Ouro Negro e BRS-MG Talismã em plantio Direto (PD) e convencional (PC). UFLA, Lavras, MG, 2006. ${ }^{(1)}$

\begin{tabular}{lcccccc}
\hline \multicolumn{1}{c}{ Cultivar } & Altura final & \multicolumn{5}{c}{ Matéria seca total } \\
\hline Ouro Negro & PD & PC & Média & PD & PC & Média \\
BRS MG Talismã & $101 \mathrm{a}$ & $79 \mathrm{~b}$ & 90 & $1537 \mathrm{~b}$ & $2492 \mathrm{~b}$ & 2014 \\
\hline Média & $88 \mathrm{~b}$ & $97 \mathrm{a}$ & 93 & $5316 \mathrm{a}$ & $4560 \mathrm{a}$ & 4938 \\
\hline
\end{tabular}

(1) Dentro de cada coluna, médias seguidas por diferentes letras diferem significativamente pelo teste de Tukey ao nível de $5 \%$ de probabilidade. 
Talismã e Ouro Negro produziram, em média, 4.938 e 2.014 $\mathrm{kg} \cdot \mathrm{ha}^{-1}$ de matéria seca da parte aérea, respectivamente, com média geral de 3.476 kg.ha-1 (Tabela 2). O valor bem inferior do acúmulo de matéria seca da cv. Ouro Negro foi influenciado pelo desempenho da cultivar no plantio direto em Madre de Deus de Minas, por se tratar de área em seu primeiro ano de incorporação ao processo produtivo e, por esta razão, com o solo ainda desbalanceado nutricionalmente (Tabela 1 ).

A análise de variância individual indicou que em todos os ensaios houve efeito das épocas de coleta sobre o acúmulo de matéria seca, com boa precisão experimental. No plantio direto, a cv. Ouro Negro apresentou incrementos pouco significativos de matéria seca total até os 24 DAE (Figura 2). Segundo Lopes et al. (1983), até o $20^{\circ}$ DAE há pequeno acúmulo de matéria seca e a partir daí há incremento da massa foliar, o qual pode perdurar por até 30 dias.

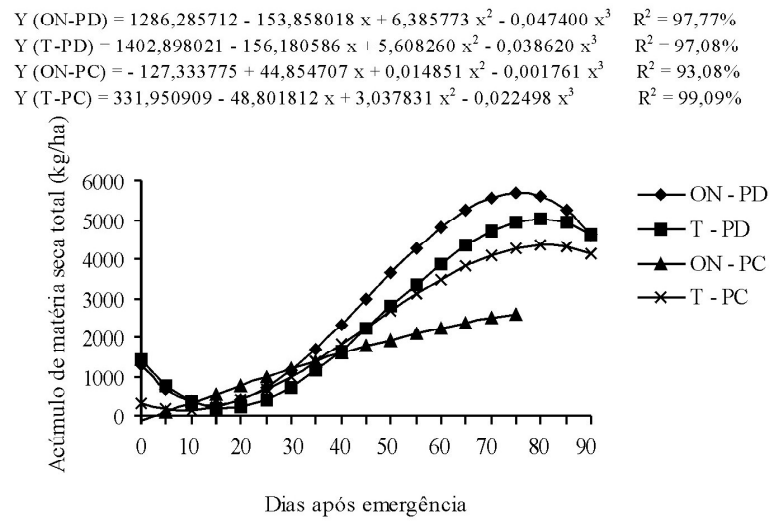

Figura 2 - Acúmulo de Matéria Seca Total $\left(\mathrm{kg} \cdot \mathrm{ha}^{-1}\right)$ em função de dias após emergência, em plantio direto(PD) e convencional (PC), cvs. Ouro Negro (ON) e Talismã (T).

O ponto de máximo acúmulo de matéria seca total se deu aos 76 DAE, quando a cv. Ouro Negro acumulou $5.670 \mathrm{~kg} \cdot \mathrm{ha}^{-1}$ (Figura 2). Este resultado foi bastante semelhante aos encontrados por Jauer et al. (2003), onde três das cultivares estudadas do tipo III apresentaram, em diferentes densidades de semeadura, máximo acúmulo variando entre 6.926,0 e 6.931,7 kg.ha-1 de matéria seca, aos 75 DAE. Segundo os mesmos autores, esse pico coincide com o período de pleno enchimento de grãos, quando estes representam $55 \%$ do peso total da planta, havendo, no fim do ciclo, ligeiro decréscimo de matéria seca total, representada pela abscisão e queda das folhas, principalmente a partir dos $80 \mathrm{DAE}$, fato que também ocorreu no presente trabalho.
A maior taxa de acúmulo de matéria seca foi obtida aos 45 DAE, quando esta apresentou valor de 132,91 kg.ha${ }^{1}$. dia $^{-1}$ (Figura 3), valor este que representa cerca de duas vezes os encontrados por Rosolem (1987).

Da mesma forma que a Ouro Negro, a cv. BRS MG Talismã, em plantio direto, apresentou incrementos de matéria seca pouco significativos até por volta de 23 DAE (Figura 2). Este fato indica que até este momento essas duas cultivares, no sistema de plantio em questão, apresentaram comportamento bastante semelhante. Entretanto, a cv. BRS MG Talismã apresentou um ciclo cultural ligeiramente maior, atingindo o ponto de máximo acúmulo de matéria seca mais tardiamante, aos 80 DAE, a partir do qual apresentou ligeiro declínio até o final do ciclo (Figura 2). Neste ponto a cv. BRS MG Talismã apresentou acúmulo de $5.028 \mathrm{~kg} \cdot \mathrm{ha}^{-1}$, resultado este bastante inferior aos encontrados por Andrade et al. (2005), estudando esta mesma cultivar, em plantio convencional.

Aos 48 DAE foi detectada a maior taxa de acúmulo de matéria seca da cv. BRS MG Talismã, corroborando com os resultados encontrados por Rosolem (1987). Neste ponto, a taxa encontrada foi de 115,29 kg.ha- ${ }^{-1} \operatorname{dia}^{-1}$ (Figura 3).

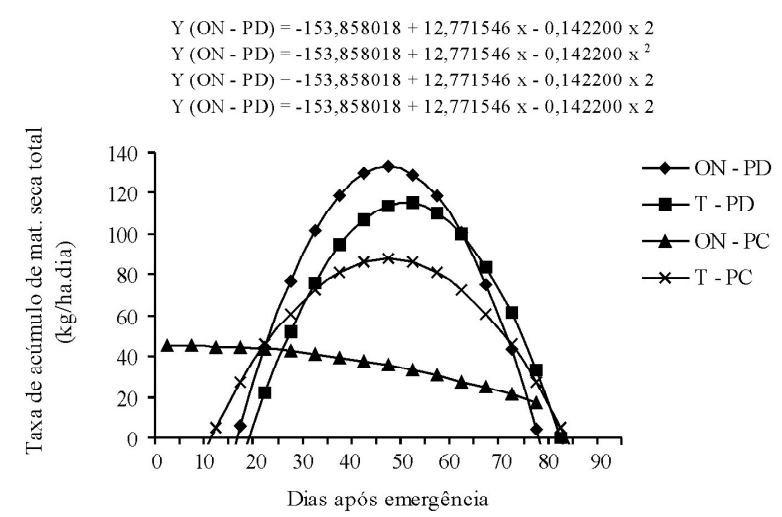

Figura 3 - Taxa de acúmulo de Matéria Seca Total $\left(\mathrm{kg} \cdot \mathrm{ha}^{-1}\right)$ em função de dias após emergência em plantio direto (PD) e convencional (PC), cvs. Ouro Negro (ON) e Talismã (T).

Em plantio convencional, a cv. Ouro Negro apresentou ciclo cultural mais precoce que no plantio direto, porém, o ponto de máximo acúmulo de matéria seca ocorreu já em plena época da colheita, os 75 DAE (Figura 2). Este resultado é bastante semelhante ao encontrado por Andrade et al. (2005), estudando esta mesma cultivar, também em plantio convencional. Entretanto, no presente trabalho houve acúmulo máximo de $2.577 \mathrm{~kg}$ ha $^{-1}$ (Figura 2 ), valor cerca de 4 vezes menor que os encontrados por aquele autor. 
A taxa de máximo acúmulo de matéria seca da cv. Ouro Negro, neste caso, se deu aos 3 DAE (Figura 3), quando alcançou 44,90 kg.ha- ${ }^{-1} \cdot \mathrm{dia}^{-1}$. Este resultado é completamente atípico e não coincide com os encontrados nos demais ensaios e por outros autores (JAUER et al., 2003; ROSOLEM, 1987), já que apresentou máxima taxa logo no início do ciclo.

\section{CONCLUSÕES}

Em plantio direto, a altura máxima foi alcançada aos 50 DAE, enquanto no plantio convencional o feijoeiro continuou crescendo até os 72-73 DAE, ocorrendo fechamento mais tardio da lavoura.

As cvs. Ouro Negro e BRS MG Talismã mostraram padrões de acúmulo de matéria seca muito próximos, com pouco incremento até os 21-24 dias após emergência. O máximo acúmulo ocorreu entre 75-76 DAE, na cv. Ouro Negro e 80-81 DAE, na BRS MG Talismã, e ambas alcançaram maiores acúmulos em plantio direto. Em geral, as maiores taxas de acúmulo de matéria seca foram verificadas entre 45-48 DAE.

\section{REFERÊNCIAS BIBLIOGRÁFICAS}

ALMEIDA, L. D.; BULISANI, E. A. Técnicas para aumentar a rentabilidade do feijoeiro. Correio Agrícola, São Paulo, v. 1, p. 236-43, 1980.

ANDRADE, C. A. B.; FONTES, P. C. R.; CARNEIRO, J. E. S.; SCAPIM, C. A.; ALBUQUERQUE, F. A. Produção de matéria seca total, taxa de crescimento absoluto e taxa de crescimento relativo de duas cultivares de feijão. In: CONGRESSO NACIONAL DE PESQUISA DE FEIJÃO, 8., 2005, Goiânia. Anais... Goiânia: UFGO, 2005. p. $835-837$.

BRANDES, D.; VIEIRA, C.; MAESTRI, M.; GOMES, F. R. Efeitos da população de plantas e da época de plantio no crescimento do feijoeiro (Phaseolus vulgaris L.): I. mudanças morfológicas e produção de matéria seca. Experientiae, Viçosa, v. 14, n. 1, p. 1-49, jul. 1972.

BULISANI, E. A. Crescimento e absorção de nutrientes em cinco cultivares de feijoeiro (Phaseolus vulgaris L.). 1994. 150 f. Tese (Doutorado em Fitotecnia) - Escola Superior de Agricultura de Luiz de Queiroz, Piracicaba, 1994.

COBRA NETTO, A. Nutrição mineral do feijoeiro (Phaseolus vulgaris L.). 1967. 91 f. Dissertação (Mestrado em Fitotecnia) - Escola Superior de Agricultura de Luiz de Queiroz, Piracicaba, 1967.
CULTIVAR de feijão talismã. Sete Lagoas: UFLA/UFV/ Embrapa/Epamig, 2002. Folder.

EMERSON, R. A. A genetic study of plant height in Phaseolus vulgaris: nebraska agricultural experimental station research. [S.1.: s.n.], 1916. (Bulletin, 7).

FERNANDEZ, F.; GEPTS, P.; LÓPEZ, M. Etapas de desarollo em la planta de frijol. In: LÓPEZ, M.; FERNADEZ, F.; SCHOOWHOVEN, A. Frijol, investigación y producción. Colômbia: CIAT, 1985. p. 61-80.

GALLO, J. R.; MIYASAKA, S. Composição química do feijoeiro e absorção de elementos nutritivos do florescimento à maturação. Bragantia, Campinas, v. 20, n. 40, p. 867-884, set. 1961.

GOMES, A. A.; ARAÚJO, A. P.; ROSSIELO, P. O. P.; PIMENTEL, C. Acumulação de biomassa, carasterística fisiológicas e rendimento de grãos em cultivares de feijoeiro irrigado e sob sequeiro. Pesquisa Agropecuária Brasileira, Brasília, v. 35, n. 10, p. 1927-37, out. 2000.

HAAG, H. P.; MALAVOLTA, E.; GARGANTINI, H.; BLANCO, H. G. Absorção de nutrientes pela cultura do feijoeiro. Bragantia, Campinas, v. 26, n. 30, p. 380-91, set. 1967.

INFORMATIVO anual das comissões técnicas regionais de feijão: cultivares de feijão recomendadas para o plantio no ano agrícola 1997/98. Goiânia: Embrapa, 1997. 29 p.

JAUER, A.; DUTRA, L. M. C.; ZABOT, L.; LUCCA FILHO, O. A.; LOSEKANN, M. E.; UHRY, D.; STEFANELO, D.; FARIAS, J. R.; LUDWIG, M. P. Análise de crescimento da cultivar de feijão Pérola em quatro densidades de semeadura. Revista da Faculdade de Zootecnia, Veterinária e Agronomia de Uruguaiana, Uruguaiana, v. 10, p. 101113, jul. 2003.

LOPES, N. F.; OLIVA, M. A.; MELGES, E.; FURTADO, M. H.; FREITAS, J. G. Crescimento, morfologia, partição de assimilados e produção de matéria seca do feijão (Phaseolus vulgaris L.) submetido a três níveis de densidade do fluxo radiante. Revista Ceres, Viçosa, v. 30, p. $451-462,1983$.

MAGALhÃES, A. C. N. Análise quantitativa do crescimento. In: FERRI, M. G. Fisiologia vegetal. São Paulo: USP, 1979. v. 1, p. 331-349. 
RIBEIRO, A. C.; GUIMARÃES, P. T. G.; ALVAREZ, V. H. (Eds.). Recomendações para o uso de corretivos e fertilizantes em Minas Gerais: $5^{\text {a }}$ aproximação. Viçosa: Comissão de Fertilidade do Solo do Estado de Minas Gerais, 1999. p. 306-307.

ROSOLEM, C. A. Nutrição e adubação do feijoeiro. Piracicaba: Associação Brasileira para Pesquisa da Potassa e do Fosfato, 1987. 91 p. (Boletim técnico, 8).
TELES NETO, M. S. Feijão: caracterização fitotécnica, extração e exportação de macronutrientes. 2001. $84 \mathrm{f}$. Dissertação (Mestrado em Fitotecnia) - Escola Superior de Agricultura de Luiz de Queiroz, Piracicaba, 2001.

XAVIER, F. E. Análise de crescimento de quatro cultivares de feijão (Phaseolus vulgaris L.) em duas épocas de plantio em Viçosa, Minas Gerais. 1976. 26 f. Dissertação (Mestrado em Fitotecnia) - Universidade Federal de Viçosa, Viçosa, 1976. 